ORIGINAL ARTICLE

\title{
The Prevalence and Severity of Carpel Tunnel Syndrome during Pregnancy
}

\author{
RAHIM KHAN ${ }^{1}$, PARVEEN SHAFI ${ }^{2}$, TARIQ AHMAD ${ }^{3}$, KHALID KHAN ${ }^{4}$, MUHAMMAD ASAD $^{5}$ \\ ${ }_{1,3}$ Assistant Professor Orthopaedics Mardan Medical Complex/BKMC, Mardan \\ ${ }^{2}$ District Specialist OBS \& Gynae Department THQ Hospital, Takht Bhai Mardan \\ ${ }^{4}$ Trainee Registrar Orthopaedics, Mardan Medical Complex/BKMC, Mardan \\ ${ }^{5}$ PostGraduate Resident Orthopaedic, Mardan Medical Complex, Mardan \\ Corresponding Author: Dr. Rahim Khan,Email:drrahimkhan79@gmail.com, Cell: +923465091619
}

\begin{abstract}
Objective: The aim of this study is to determine the prevalence and severity of carpel tunnel syndrome during pregnancy.

Study Design: Descriptive/cross-sectional study

Place and Duration: Orthopaedic Department Mardan Medical Complex/BKMC and OBS \& Gynae department THQ Hospital Takht Bhai Mardan from June 2019 to June 2021.

Methods: Two hundred pregnant women were enrolled in this study. Patients were having18-45years of ages. Patients' detailed demographics including age, residency, economic status and body mass index were recorded after taking informed written consent. Clinical test Phalen and Tinel were used to diagnose the CTS. CTS among patients were calculated in terms of mild, moderate and severity. Complete data was analyzed by SPSS 24.0version.

Results: Mean age of the patients was $29.86 \pm 6.75$ years with mean BMI $27.24 \pm 2.48 \mathrm{~kg} / \mathrm{m}^{2}$. Most of the patients $80(40 \%)$ were from third trimester followed by $2^{\text {nd }}$ trimester $70(35 \%)$ and the rest were $50(25 \%)$ women from first trimester. 90 (45\%) women were educated and 70 (35\%) were from urban areas. Among 200 pregnant women, frequency of carpal tunnel syndrome was found among 60 (30\%) patients. There were $25(41.7 \%)$ cases had mild CTS, 15 (25\%) patients had moderate and 20 (33.3\%) patients had severe CTS.

Conclusion: We concluded in this study that the prevalence of CTS among pregnant women was high and most of the patients had mild to severe CTS. It is more prevalent among the patients of third semester.

Keywords: Pregnancy, Carpel Tunnel Syndrome, Severity, Women
\end{abstract}

\section{INTRODUCTION}

As the name suggests, carpal tunnel syndrome (CTS) is a condition in which the median nerve is entrapped in the carpal tunnel of the wrist joint by its flexor retinaculum [1]. In different research papers, the prevalence of CTS is reported differently. There is a prevalence of 2.7 percent in the United States of America Men/women ratios range from $3: 1$ to $10: 1$. In 78 percent of patients, bilateral CTS is diagnosed clinically, and in 50 percent of patients, it is diagnosed by electrodiagnostic studies [2]. CTS is caused by a variety of reasons, including pregnancy [3,4] Given that nearly all women go through pregnancy multiple times, examining its effect on creating or exacerbating CTS can be beneficial. Numbness, tingling, and burning in the median nerve area are common complaints[2].

Tinel, Phalen, and median nerve compression, which induce or increase symptoms, are traditional clinical tests for diagnosing CTS in clinical examination. Using electrodiagnostic tests performed by a qualified electromyographer is the most accurate diagnostic procedure, with an overall sensitivity of 49-84 percent and specificity of 95 percent $[1,2]$.

Depending on the situation, CTS can be treated with wrist splints, corticosteroid injections in the carpal tunnel, or surgery to release the median nerve. To prevent CTS relapses during subsequent pregnancies, it is important to diagnose CTS early and adopt noninvasive treatment options.

Standard electrodiagnostic procedures have not been employed in CTS research undertaken on pregnant women to yet[4-6]. As a result of this, investigations on CTS and pregnancy have been carried out on pregnant women in the third trimester utilizing clinical and electrodiagnostic tests[7,8].

Symptoms of Carpal Tunnel Syndrome include discomfort, numbness and tingling along the median nerve distribution in the hands that can extend to the upper arms. The prevalence of CTS was shown to be higher among women in previous research. It was suggested that females are more susceptible to CTS than males due of their morphology [9]. Wallace and Cook described two occurrences of CTS in pregnancy in 1957 and performed surgical decompression [10]. "Pressure as the source of such symptoms" is the emphasis of the paper CTS in pregnancy was the subject of further research and theorization. Despite the fact that more research is being done on CTS in pregnancy, it is still unclear how often it is and how severe it can be. Study by Voitk et al. indicated that $24,9 \%$ of pregnant women reported hand sensations in the median nerve distribution, with $51 \%$ finding the symptoms irritating, $42 \%$ reporting that it interfered with their functions, and $29 \%$ claiming that it interfered with their sleep [11] According to Voitk and colleagues, just 49 percent of patients reported symptoms to their doctor, and only 16 percent of those patients received treatment or advice.

As a result of numerous studies, it has been established that the first symptoms of CTS emerge most frequently during the third trimester [12,13], rather than having to endure them throughout the pregnancy. But there isn't much research on how CTS affects pregnant women, especially in the third trimester.[14,15] In spite of the fact 
that CTS may have been the least of these women's concerns during pregnancy and that the majority of them saw a resolution or improvement after delivery, the truth remains there[16].

The aim of this study is to determine the prevalence and severity of carpal tunnel syndrome during pregnancy.

\section{MATERIAL AND METHODS}

This descriptive/ cross-sectional study was conducted at Mardan Medical Complex and THQ hospital Takht Bhai Mardanand comprised of 200 pregnant women. Patients' detailed demographics including age, residency, socioeconomic status and body mass index were calculated after taking informed written consent. Non pregnant women, patients had hypothyroidism, diabetes, below 18 years and above 45years of age were excluded from this study.

Patients were aged between $18-45$ years. Clinical test Phalen and Tinel were used to diagnose the CTS. These women were sent to a physiatrist for electrodiagnostic examination because they reported clinical symptoms of CTS and a positive Tinel and/or Phalen Using a wristmounted electrode array, we examined sensorimotor distal latency of the median and ulnar nerves, as well According to accepted criteria for ulnar and median nerve conduction velocity, CTS has been identified. Their nerve conduction velocity was measured by the US Electrodiagnostic Society and they were categorized into three groups: mild, average, and severe. Therefore, 30-40 m/s, 24-29 m/s, and $24 \mathrm{~m} / \mathrm{s}$ were classified mild, moderate, and severe, respectively. Complete data was analyzed by SPSS 24.0 version. Frequencies and percentages were used for categorical variables.

\section{RESULTS}

Mean age of the patients was $29.86 \pm 6.75$ years with mean BMI $27.24 \pm 2.48 \mathrm{~kg} / \mathrm{m}^{2}$. Most of the patients $80(40 \%)$ were from third trimester followed by $2^{\text {nd }}$ trimester $70(35 \%)$ and the rest were 50 (25\%) women from first trimester. 90 $(45 \%)$ women were educated and 70 (35\%) were from urban areas.(table 1)

Table 1: Baseline details demographics of enrolled cases

\begin{tabular}{|l|l|l|}
\hline Variables & Frequency $(\mathbf{n}=\mathbf{2 0 0})$ & \%age \\
\hline Mean age & $29.86 \pm 6.75$ & \\
\hline Mean BMI & $27.24 \pm 2.48$ & \\
\hline Trimester & 50 & 25 \\
\hline I & 70 & 35 \\
\hline II & 80 & 40 \\
\hline III & 70 & 35 \\
\hline Residency & 130 & 65 \\
\hline Urban & 45 \\
\hline Rural & 90 & 55 \\
\hline Education Status & 110 & \\
\hline Yes & $90 a r p a l$ \\
\hline No &
\end{tabular}

Among 200 pregnant women, frequency of carpal tunnel syndrome was found among 60 (30\%) patients.(table 2)

Table 2: Prevalence of CTS among pregnant women

\begin{tabular}{|l|l|l|}
\hline Variables & Frequency $(\mathbf{n}=200)$ & \%age \\
\hline CTS & 60 & 30 \\
\hline Yes & 140 & 70 \\
\hline No &
\end{tabular}

Among 60 cases of CTS positive, there were 25 (41.7\%) cases had mild CTS, 15 (25\%) patients had moderate and 20 (33.3\%) patients had severe CTS.(table 3)

Table 3: Association of CTS in terms of mild, moderate and severe

\begin{tabular}{|l|l|l|}
\hline Variables & Frequency & \%age \\
\hline CTS & 25 & 41.7 \\
\hline Mild & 15 & 25 \\
\hline Moderate & 20 & 33.3 \\
\hline Severe & 60 & 100 \\
\hline Total & \multicolumn{2}{|l|}{} \\
\hline
\end{tabular}

\section{DISCUSSION}

In this descriptive cross-sectional study 200 pregnant women were presented to calculate the prevalence of carpal tunnel syndrome. In our study women were aged between $18-45$ years with mean age $29.86 \pm 6.75$ years. Mean BMI of the patients were $27.24 \pm 2.48 \mathrm{~kg} / \mathrm{m}^{2}$. Majority of the patients $40 \%$ were from third trimester. These findings were comparable to the previous some studies. $[17,18]$ We found that $90(45 \%)$ women were educated and $70(35 \%)$ were from urban areas. Research that used electrodiagnosis found a high prevalence of CTS in pregnancy; whereas, studies that used solely clinical diagnostics found a low prevalence of CTS in pregnancy.

According to Padua et al. and Pazzaglia [19] , the incidence of CTS during pregnancy is more than $50 \%$. Voitk and colleagues report that it is $34 \%$, and Stolp et al. report that it is less than 1 percent. $28 \%$ and $43 \%$ of women were affected in two further third trimester studies, respectively. [6,7] In our study prevalence of CTS was found among $30 \%$ pregnant women. These results were comparable to the above mentioned previous studies. When it came to pregnancy, the incidence of unilateral and bilateral CTS was practically identical, with bilateral instances being more common than unilateral it doesn't matter if the CTS is unilateral or bilateral, there's no association between the severity of the CTS on the other hand, in one of Padua et.al's research on CTS in a broad population, bilateral cases were greater, although there was no statistical link. [16]

Another study found that the third trimester had the highest rate of (26.6 percent). It is also necessary to conduct electrodiagnosis for symptomatic instances since one-third of symptomatic cases have definite electrodiagnostic criteria, but electrodiagnosis is not required for asymptomatic pregnant women (50\%) because there were no positive electrodiagnostic findings. [20]Women in the third trimester exhibited CTS symptoms in 62 percent of cases, and electrodiagnosis revealed CTS in 50 percent of cases. [21] According to another study of 200 pregnant women in the third trimester, 28 percent of them had a definitive CTS diagnosis, and 80 percent of them were asymptomatic[8], which was similar to our study.

In our study, among 60 cases of CTS positive, there were $25(41.7 \%)$ cases had mild CTS, 15 (25\%) patients had moderate and $20(33.3 \%)$ patients had severe CTS.[22,23]A high incidence of CTS-related signs and symptoms during the third trimester of pregnancy, compared to the prevalence of CTS in general, suggests that pregnancy can be regarded as a risk factor for CTS. In 
the majority of cases, the symptoms began in the third trimester of pregnancy and were minor, which is in line with the literature. Obstetric CTS has an excellent prognosis, but its great prevalence and the difficulties it might cause at a time when women need full functional capacity of their hands to care for their infants underscores the need for a timely diagnosis and treatment of CTS during pregnancy.[24,25]

\section{CONCLUSION}

We concluded in this study that the prevalence of CTS among pregnant women was high and most of the patients had mild to severe CTS. It is more prevalent among the patients of third trimester with severe pain.

\section{REFERENCE}

1. Johnson EW, Hennessey WJ. Carpal tunnel syndrome. In: Johnson EW, Pease WS, editors. Practical electromyography. 3rd ed. USA: Williams \& Wilkins; 1997. pp. 195-8.

2. Dumitru D, Zwarts MJ. Focal peripheral neuropathy. In: Dumitru D, Zwarts MJ, Amanto AA, editors. Electrodiagnostic medicine. 2nd ed. Philadelphia: Hanley \&Belfus; 2002. pp. 1047-126.

3. Szabo RM, Madison M. Carpal tunnel syndrome. OrthopClin North Am. 1992;123:109-30.

4. McLennan HG, Oats JN, Walstab JE. Survey of hand symptoms in pregnancy. J Med Aust. 1987;147:542-8.

5. Stolp-Smith KA, Pascoe MK, Ogburn PL. Carpal tunnel syndrome in pregnancy: frequency, severity, and prognosis. Arch Phys Med Rehabil. 1998;79:1285-7.

6. Ordbieg G. Carpal tunnel syndrome in pregnancy. ActaObstetGynecol Scand. 1987;66:235-7.

7. Pazzaglia CC. Multicenter study on carpal tunnel syndrome and pregnancy incidence and natural course. Asta Neuro Chir Suppl. 2005;92:35-9.

8. Atisook R, Benjapibal $M$, Sunsaneevithayakal $P$, Roongpisuthipoog A. Carpal tunnel syndrome during pregnancy, prevalence and blood level of pyridoxine. J Med Assoc Thailand. 1995;78:410-4.

9. Pacek CA, Tang J, Goitz RJ, et al.: Morphological analysis of the carpal tunnel. Hand 2010, 5: 77-81. 10.1007/s11552-0099220-9

10. Wallace Cook AW: Carpal tunnel syndrome in pregnancy: a report of two cases. Am J ObstetGynecol 1957,73(6):13331336.

11. Voitk AJ, Mueller JC, Farlinger DE, Johnston RU: Carpal tunnel syndrome in pregnancy. Can Med Assoc J 1983, 128: 278-81

12. Ferry $S$, Hannaford $P$, Warskyj $M$, et al.: Carpal tunnel syndrome: A nested case-control study of risk factors in women. Am J Epidemiol 2006,15(6):566-74

13. Stolp-Smith KA, Pascoe MK, Ogburn PL Jr: Carpal tunnel syndrome in pregnancy: Frequency, severity, and prognosis. Arch Phys Med Rehabil 1998, 79: 1285-7. 10.1016/S0003-9993(98)90276-3

14. Turgut $F$, Cetinsahinahin $M$, Turgut $M$, Bolukbasi $O$ : The management of carpal tunnel syndrome in pregnancy. $J$ ClinNeurosc 2001,8(4):332-4.

15. Baumann F, Karlikaya G, Yuksel G, et al.: The subclinical incidence of CTS in pregnancy: Assessment of median nerve impairment in asymptomatic pregnant women. Neurol, Neurophysiol and Neurosc 2007, 3: 1-9

16. Padua L, Aprile I, Caliandro P, et al.: Symptoms and neurophysiological picture of carpal tunnel syndrome in pregnancy. ClinNeurophysiol 2001, 112: 1946-51.

17. Atroshi I, Lyren PE, Gummesson C: The 6-item CTS symptoms scale: A brief outcome measure for CTS. Springer Sciences and Business Media 2009, 18: 347-58.

18. Rozali, Z.I., Noorman, F.M., De Cruz, P.K. et al. Impact of carpal tunnel syndrome on the expectant woman's life. Asia Pac Fam Med 11, 1 (2012).

19. Megan S. Gooding, Victor Evangelista, Leonardo Pereira, Carpal Tunnel Syndrome and Meralgia Paresthetica in Pregnancy, Obstetrical \& Gynecological Survey, 10.1097/OGX.0000000000000745, 75, 2, (121126), (2020).

20. Pazzaglia C, Caliandro P, Aprile I, Mondelli M, Foschini M, Tonali $P$, Luca Padua and Italian CTS and others entrapment Study Group: Multicenter study on carpal tunnel syndrome and pregnancy incidence and natural course. ActaNeurochirurgicaSupplementum 2005, 97, Part I: 35-39.

21. Shaafi $\mathrm{SH}$, NaimianSh, Iromlou $\mathrm{H}$, SayyahMelli $\mathrm{M}$ Prevalence and severity of carpal tunnel syndrome (CTS) during pregnancy based on electerophysiology studies. Shiraz E-Med J. 2006;7:177-81.

22. Padua L, Pazzaglia C, Mondelli M, Liotta GA. Symptoms and neurophysiological picture of carpal tunnel syndrome in pregnancy. ClinNeurophysiol J. 2001;112:1946-51

23. Anna M. Lipowska, Amandeep K. Shergill, Ergonomics in the unit: modeling the environment around the endoscopist, Techniques and Innovations in Gastrointestinal Endoscopy, 10.1016/j.tige.2020.12.004, (2020).

24. Gladys Alexandra Dias de Oliveira, João Marcos Bernardes, Elisiane de Souza Santos, Adriano Dias, Carpal tunnel syndrome during the third trimester of pregnancy: prevalence and risk factors, Archives of Gynecology and Obstetrics, 10.1007/s00404-019-05233-6, (2019).

25. Berggren EK, Groh-Wargo S, Presley L, Hauguel-de Mouzon S, Catalano PM (2016) Maternal fat, but not lean, mass is increased among overweight/obese women with excess gestational weight gain. Am J ObstetGynecol 214(6):745.e15

26. Guan W, Lao J, Gu Y, Zhao X, Rui J, Gao K (2018) Casecontrol study on individual risk factors of carpal tunnel syndrome. ExpTher Med 15(3):2761-2766 